The International Journal of Indian Psychology

ISSN 2348-5396 (e) | ISSN: 2349-3429 (p)

Volume 5, Issue 1, DIP: 18.01.102/20170501

DOI: $10.25215 / 0501.102$

http://www.ijip.in | October-December, 2017

Original Research Paper

\title{
Estimation of the Stress Index in Patients of Different Age \\ Categories
}

\author{
Tuziak Bogdan ${ }^{1} *$
}

\section{ABSTRACT}

Stress is a body's response to mental or emotional pressure. The frequency of stress among different age categories is a widely discussed topic. The aim of this study was to evaluate stress levels in three groups of patients (age range from 18 to 35, from 35 to 60, and from 60 and older) at "Podolie" (Satanov) sanatorium in Ukraine and to identify the most relevant theory for the obtained results. The author recruited 344 patients diagnosed with asthmatics by clinical and radiological criteria (cases) and 5 with pneumonia. The case-control study in patients was provided with personal confirmed permission of each patient. Permission of the director of sanatorium, chief medical officer and pulmonologist was obtained to use the obtained data with AngioScan-01 cardiovascular system diagnostic device for stress index evaluation. Clinical analysis showed a scarce statistically significant association of stress levels with some of the age categories. The multivariated analysis shows a direct association of age and stress predisposition. Significant age-related differences in stress levels among the patients were identified. The results suggest that there is a strong association between stress levels and age. A direct correlation of the stress index with the age factor of patients was found.

Keywords: Coping, Stress Resistance, Heart Rate, Stress Index, Age

The tendency of the organism to resist changes in order to maintain a stable, relatively constant internal environment is called Homeostasis (Bernard, 1865; Cannon, 1929). The term "stress" primarily was used by Selye (1956) to represent the effects of anything that seriously threatens homeostasis (Selye, 1956). The chemical or biological agent, external stimulus, environmental condition or an event that causes stress to an organism is referred to as "stressor" (Tadatoshi et al., 2006) and the response to the stressor is referred to as "stress response" (Gozhenko et al., 2009). Nevertheless, stress responses have been evolved as adaptive processes (Shelley et al., 2012). The stress response is regulated by corticotropinreleasing factor (CRF) and serotonin (5-HT) (Hemrick-Luecke and Evans, 2002). Selye observed that severe, prolonged stress responses might lead to tissue damage and disease. He

\footnotetext{
${ }^{1}$ BJur, MPsy; Affiliated Researcher, Department of Biotechnological and Applied Clinical Sciences, University of L'Aquila, L'Aquila, Italy

*Responding Author

(C) 2017 Bogdan T; licensee IJIP. This is an Open Access Research distributed under the terms of the Creative Commons Attribution License (www.creativecommons.org/licenses/by/2.0), which permits unrestricted use, distribution, and reproduction in any Medium, provided the original work is properly cited.
} 
also found that there are several ways to cope with stress ("The Silent Denial of Stress in a Competitive World", 2012) by means of social support for example (Kalat, 2013), which is true for all age categories. There are some differences in animal stress responses associated with aging and sex (Yamada et al., 2015). The young healthy individuals are more stress resistant than older or unhealthy individuals, which have long-term effects (Schneiderman, 2005). There is no precise information about the stress index of individuals of different age categories. Some researchers founded the relation between the stress response and age (Mroczek and Almeida, 2004) but others didn’t (Röcke et al., 2009). The recent theories (Charles and Piazza, 2009; Charles, 2010; Wrzus et al., 2013) are also based on two opposite results associated with better or worse emotional well-being in aged individuals. The SAVI (Strength and Vulnerability Integration) theory is based on acknowledgment of both theory versions, basing on the results that demonstrated that older adults reported similar or worse levels of well-being than younger adults (Charles,2010). So, today there are three theories about the age influence on stress response.

\section{Aims}

The present study aims is: a) to carry out test using the AngioScan-01 predictions of correlation between aging and stress index in a sample of young people (18-35), middle-aged (35-60), and older adults (above 60); b) to perform statistical analysis of the data obtained; c) to identify the most relevant theory according to the mean value of stress index.

\section{Actuality}

Currently, there's insufficient attention to association between stress frequency in different age categories. The main attention is paid to chronic distress and its treatment, while the importance of the stress index in different ages becomes of secondary scientific interest. The research on this argument in our days can be complementary to the treatment of actual researches in this field and can allow to understand the prevalence of stress in a particular age group.

\section{METHODOLOGY}

\section{Subjects}

Participants included 349 adults in course of treatment or disease prevention in "Podilia" Ukrainian sanatorium ranging from young adulthood to old age (mean age $=50,13 \pm 0,05$; aged 18-82). The sample included 203 (58,17 \%) females and 146 (41,83\%) males. The sample mainly included the representatives of the Khmelnizky region. Participants were recruited from an existing database of persons who hadn't psychological, psychiatric and neurological disorders. All participants taking anxiety or depression medications were excluded. 


\section{Estimation of the Stress Index in Patients of Different Age Categories}

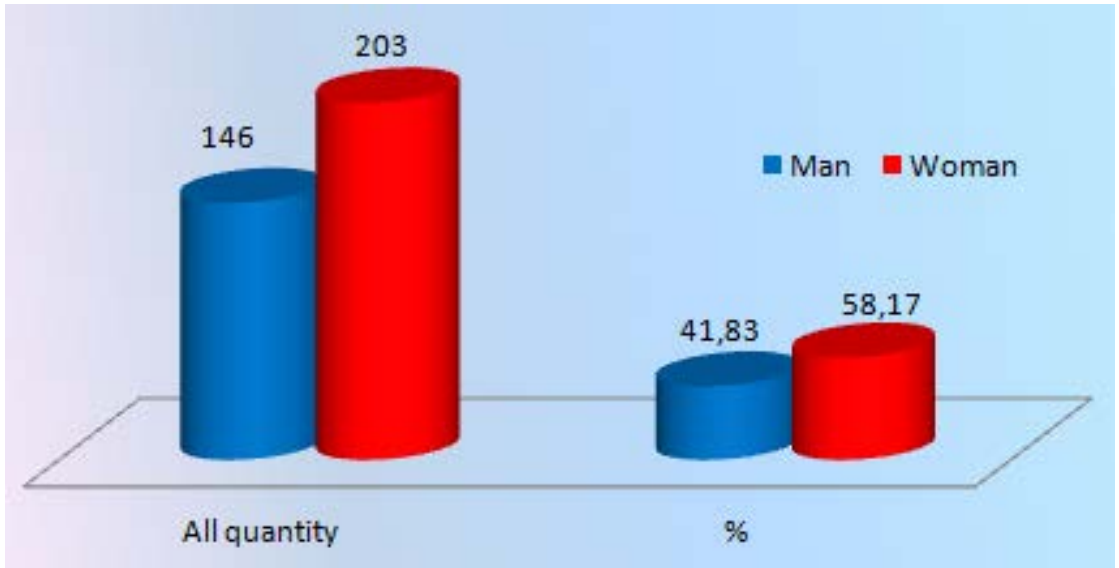

\section{Graph 1: The gender characteristics of subjects}

\section{Clinical assessments and ethical consent}

The study involved the assessment of the Ukrainian sample of patients of "Podilia" Sanatorium with the AngioScan-01 diagnostic device evaluating the stress index through the pulmonologist's medical examination. The stress index is also known as the stress index of regulatory systems or the Bayevsky index, which allows you to assess the variability of the heart rate. The parameter characterizes the state of cardiovascular system regulating centers (Cherepanova, 1997; Tashcheva, 2000). The standard Baevsky index is the index value from 50 to 150 . With an exercise load, chronic fatigue, a decrease in body reserves with age, the index ranges from 150 to 500. In case of angina, psycho-physiological overwork, significant psychological and emotional stress, the stress index reaches values from 500 to 900 . The index above 900 indicates a significant violation of regulatory mechanisms, and such an index is observed in case of the preinfarction syndrome (Kun, 2003; Seley, 1979). Patients were divided into three groups according to age: from 18 to 35 years, from 35 to 60 years and from 60 years and older. The average value of the stress index in all three groups was calculated. Each group was divided into 4 categories. The first category consisted of those patients who had a normal stress index; the second category consisted of patients with an index of 150 to 500, a third from 500 to 900, and the fourth - over 900.

All subjects gave written informed consent before they participated in the study. In addition, the permission of the director of sanatorium, chief medical officer and pulmonologist to use the obtained data was obtained.

\section{Statistical Analysis}

To perform the statistical analysis, MED-CALC statistical software (Ostend, Belgium), version 14, was used.

\section{RESULTS}

The average stress index of all studied patients was $199.1 \pm 0.05$, which is 1.33 times higher than the upper limit of the norm (150). The stress index within the norm limits (50-150) was determined in 199 patients (57.02\%). The stress index from 150 to 500 was determined in 
125 patients (35.82\%) and from 500 to 900 in 17 patients (4.87\%), over 900 in 8 patients (2.29\%).

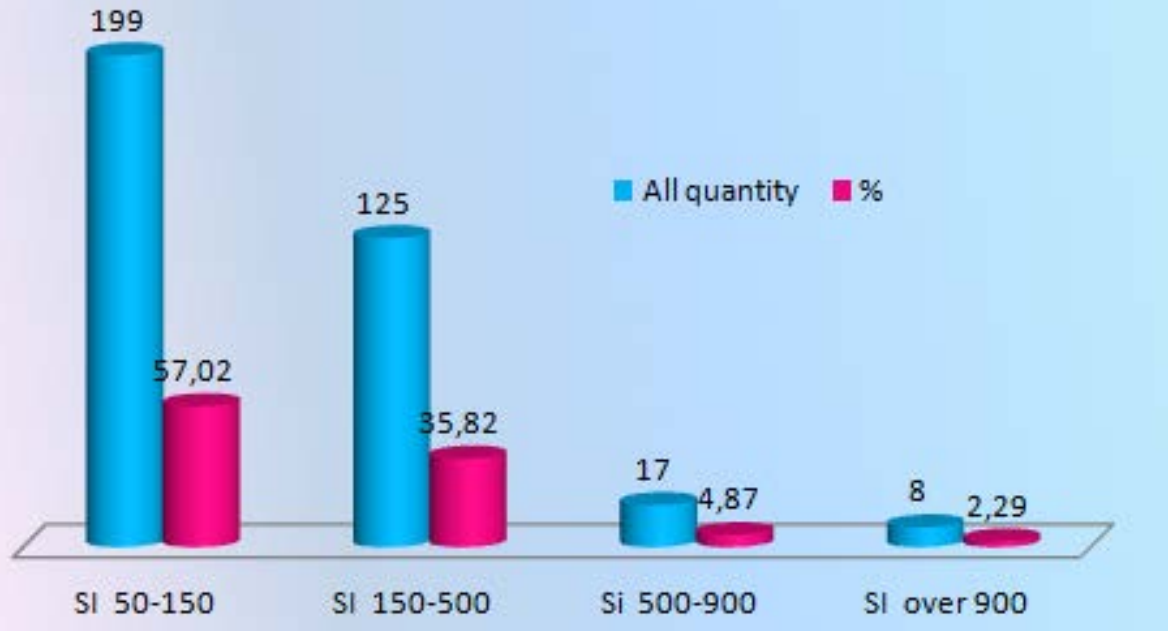

\section{Graph 2: The stress index (SI) of all subjects}

The first study group, that is, between 18 and 35 years of age, comprised 90 patients (60 women and 30 men) $-25.79 \%$ of all subjects. The average age of the patients in this group was $28.71 \pm 0.05$ years. The normal value of the stress index (50-150) was determined in 70 patients of the first group (77.78\%), the index from 150 to 500 in 19 patients (21.11\%), over 900 in 1 patient (1.11\%). The stress index from 500 to 900 is not diagnosed in any patient. Thus, in this group, there are 20 patients (22.22\%) with an increased stress index. The average stress index for this group was $117.26 \pm 0.05$, which is within the norm limits (50150).

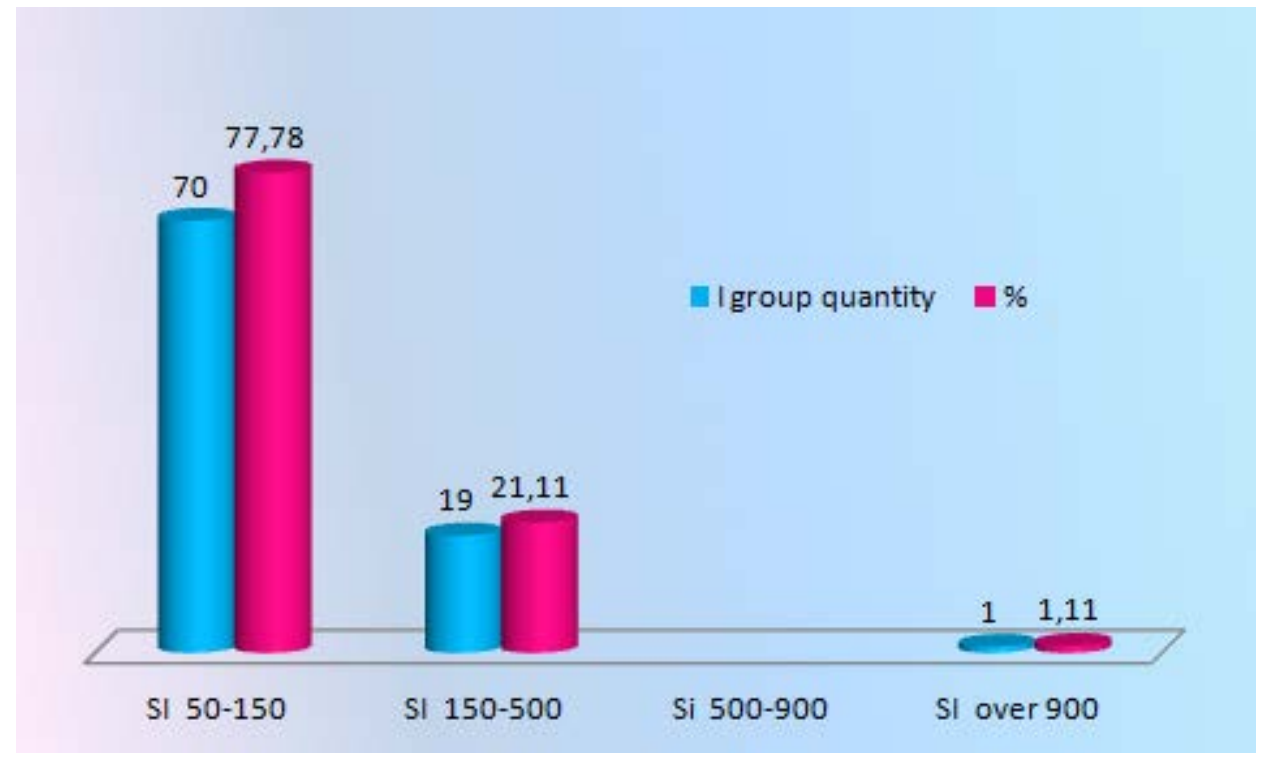

Graph 2: The stress index (SI) of first group

The second group, aged 35 to 60 years, consisted of 128 patients (66 women and 62 men) $36.67 \%$ of all subjects. The average age of the patients was $49.43 \pm 0.05$ years. A normal 


\section{Estimation of the Stress Index in Patients of Different Age Categories}

stress index was defined in 74 patients (57.81\%), an index from 150 to 500 in 45 patients (35.16\%), from 500 to 900 in 7 patients (5.47\%), over 900 in two patients (1.56\%). Thus, in this group, there are 54 patients (42.19\%) with an increased stress index, which is 1.9 times greater than that of the first group. The average stress index of this group was $201.52 \pm 0.05$, which is $1.72 \pm 0.05$ times higher than that of the first group of the study and $1.34 \pm 0.05$ times higher than the upper limit of the norm (150).

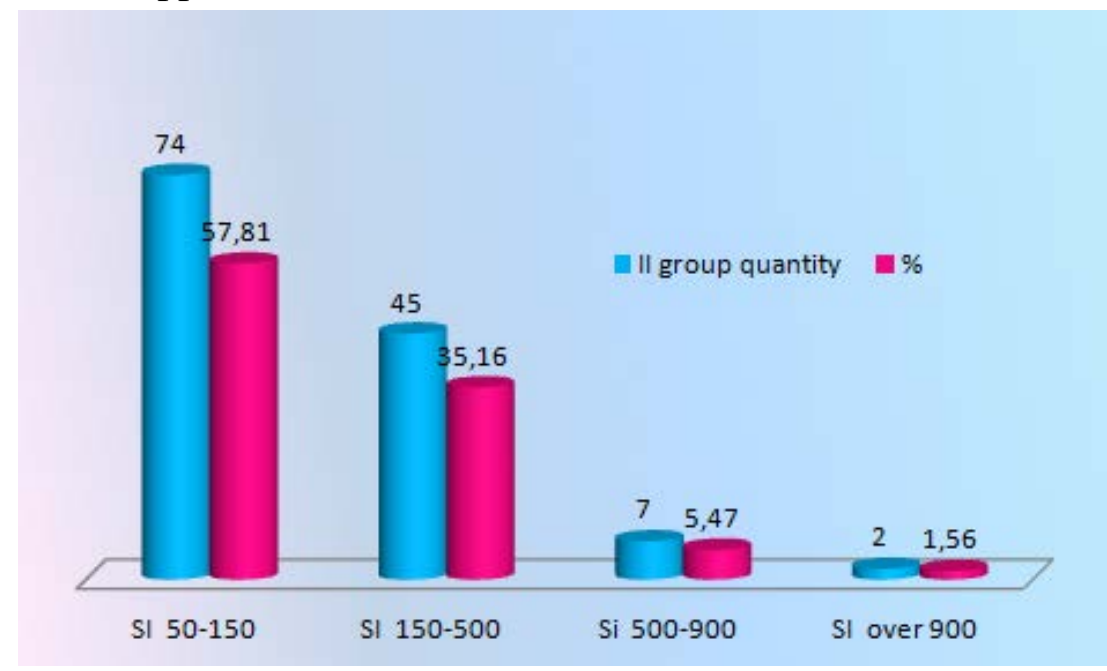

\section{Graph 3: The stress index (SI) of second group}

In the third group, aged over 60, there were 131 patients ( 77 women and 54 men) $-37.54 \%$ of all subjects. The mean age of this group was $65.54 \pm 0.05$ years. The maximum age is 82 years ( 1 patient). The stress index within the norm was diagnosed in 55 patients $(41.98 \%)$, the index from 150 to 500 - in 61 patients (46.56\%), from 500 to 900 - in 10 patients (7.63\%), over 900 - in 5 patients (3.82\%). Thus, in this group 76 patients (58.02\%) have an increased stress index, which is 1.38 times higher than that of the second group and 2.61 times more than that of the first group. It follows that the number of patients with an increased stress index increase with age, but the number of patients with a normal stress index value decrease. The average stress index of this group was $252.98 \pm 0.05$, which is $1.26 \pm 0.05$ higher than that of the second group, $2.16 \pm 0.05$ higher than that of the first group and $1.69 \pm 0.05$ above the upper limit of the norm (150).

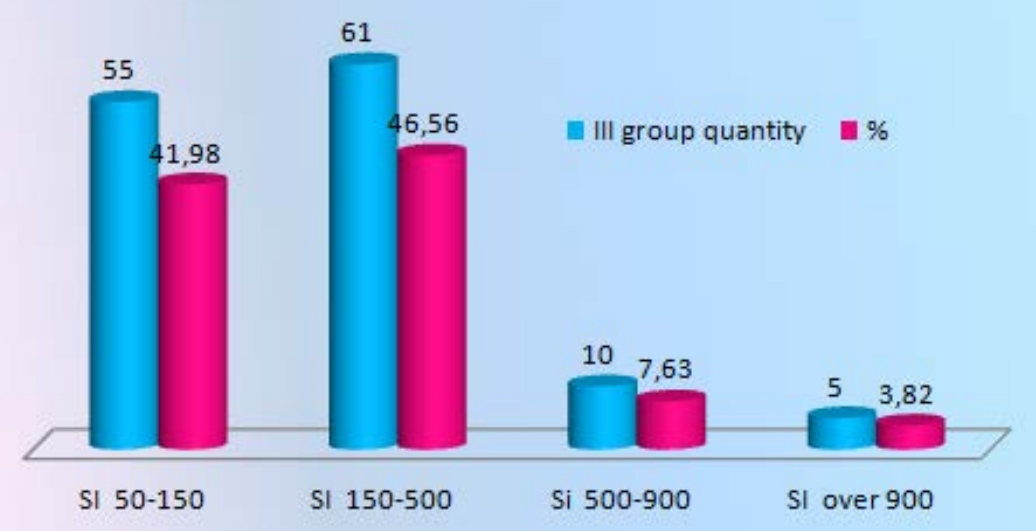

\section{Graph 4: The stress index (SI) of third group}

(C) The International Journal of Indian Psychology, ISSN 2348-5396 (e)| ISSN: 2349-3429 (p) | 16 


\section{Estimation of the Stress Index in Patients of Different Age Categories}

The number of patients with a normal index of stress with age decrease: in the first group there were 70 (77.78\%) such patients, in the second group - 74 (57.81\%), in the third group 55 (41.98\%). The number of people with an increased stress index increase with age: in the first group there were 20 patients (22.22\%), in the second group - 54 patients (42.19\%), in the third group - 76 patients (58.02\%).

\section{DISCUSSION}

The author investigated associations between stress index in a sample of young people (18-35 years), middle-aged (35-60 years), and older adults (from 60 years old) using the AngioScan01 diagnostic device.

High frequency of stress index was expected in second $201.52 \pm 0.05$ and third group 252.98 \pm 0.05 . The average stress index of the first study group was $117.26 \pm 0.05$ and the second study group showed in $1.72 \pm 0.05$ times higher results than that of the first group predicting higher stress levels in subjects above the age of 35 and higher stress predisposition in people above 60 years. Although the average stress index of the third study group was $252.98 \pm 0.05$, which is in $1.26 \pm 0.05$ times higher than that of the second group and $2.16 \pm 0.05$ times higher than that of the first group.

The purpose of this study was to determine the prevalence of stress in some specific aging group of people in a community sample of adults free from current physical or mental health disorders. First, it was hypothesized that high stress index wouldn't be associated with the specific aging group. Second, a stress frequency was hypothesized to be equally distributed in three patients' categories. Hence, it was predicted that the high levels of stress would be associated with the age. Third and finally, it was predicted that gender would be associated with stress frequency in the all groups. The present results yielded support for the unexpected hypothesis that was initially discarded to have realizing probability.

Across the sample, low levels of stress were related to fewer age and high levels of stress were related to the greatest age. Together, these results indicate that the young organism has stronger coping response.

According to the obtained search results, it's possible to identify the most corresponding related theory. Finally, it's obvious that these research results are the reproduction of Mroczek DK and Almeida DM research results. In this sense, it was demonstrated that the aging theory influence on stress levels is reproducible and can be widely applied as a theory. Consequently, these data provide a novel contribution to this area of stress investigation.

\section{CONCLUSION}

According to the obtained results, it's possible to conclude that the stress index correlates with the age factor. A direct correlation of the stress index with the age factor of patients was found. In this study, the author has shown that the stress index of the persons over 60 years is 
higher than in other aging groups. In this way this research suggests the reproducibility of the theory of age dependent high levels of stress.

\section{LIMITATION}

Several limitations of the study must be noted. The major limitation of this study is the recruited participants with diagnosis of asthma and pneumonia. Moreover, the study was conducted among the patients in a single institution, suggesting that some responses may be institution-specific and may therefore not be applied to other institutions in Ukraine or other countries. For these reasons, the author urges readers to exercise caution in extending our results and conclusions.

\section{Acknowledgements}

We acknowledge the contribution of the medical personal of the Ukrainian sanatorium "Podilia”, all the participants and the professor Daniel Mroczek.

Conflict of Interests: The author declared no conflict interests.

\section{REFERENCES}

"The Silent Denial of Stress in a Competitive World". The Silent Denial of Stress in a Competitive World. 2012-03-17. Retrieved 2012-03-17.)

Bernard C. (1865). An Introduction to the Study of Experimental Medicine. Transl. HC Greene. New York: Collier; 18651961.

Cannon WB. (1929). Bodily Changes in Pain, Hunger, Fear and Rage. 2nd ed. New York: Appleton;

Charles ST, Piazza JR. (2009). Age differences in affective well being: Context matters. Social and Personality Psychology Compass.; 3(5):711-724.

Charles ST. (2010). Strength and vulnerability integration: a model of emotional well-being across adulthood. Psychol Bull. Nov; 136(6):1068-91.

Cherepanova E.M. (1997). Psihologicheskij stress: Pomogi sebe i rebenku. Kniga dlja shkol'nyh psihologov, roditelej i uchitelej. - 2-e izd. - M.: Izdatel'skij centr «Akademija», p. 14.

Gozhenko, A; Gurkalova, I.P.; Zukow, W; Kwasnik, Z (2009). PATHOLOGY - Theory. Medical Student's Library. Radom. pp. 270-275.

Hemrick-Luecke SK, Evans DC. (2002). Comparison of the potency of MDL 100,907 and SB 242084 in blocking the serotonin (5-HT)(2) receptor agonist-induced increases in rat serum corticosterone concentrations: evidence for 5-HT(2A) receptor mediation of the HPA axis. Neuropharmacology.42(2):162-9. Epub 2002/01/24. pmid:11804612.

Kalat, J. W. (2013). Biological Psychology. p. 383

Kun D. (2003). Osnovy psihologii. Vse tajny povedenija cheloveka. - SPb.: Prajm-Evroznak, p. 864

Mroczek DK, Almeida DM. (2004). The effect of daily stress, personality, and age on daily negative affect. J Pers. Apr; 72(2):355-78.)

Röcke, Li, \& Smith. (2009) 
Saegusa Y, Takeda H, Muto S, Nakagawa K, Ohnishi S, Sadakane C, et al. Decreased plasma ghrelin contributes to anorexia following novelty stress. Am J Physiol Endocrinol Metab. 2011;301(4):E685-96. Epub 2011/06/30. pmid:21712530.)

Sato, Tadatoshi; Yamamoto, Hironori; Sawada, Naoki; Nashiki, Kunitaka; Tsuji, Mitsuyoshi; Muto, Kazusa; Kume, Hisae; Sasaki, Hajime; Arai, Hidekazu; Nikawa, Takeshi; Taketani, Yutaka; Takeda, Eiji (October 2006). "Restraint stress alters the duodenal expression of genes important for lipid metabolism in rat".Toxicology. 227 (3): 248261.doi:10.1016/j.tox.2006.08.009. PMID 16962226.)

Schneiderman N.; Ironson G.; Siegel S. D. (2005). "Stress and health: psychological, behavioral, and biological determinants". Annual Review of Clinical Psychology. 1 (1):607-628. PMC 2568977. PMID 17716101

doi:10.1146/annurev.clinpsy.1.102803.144141.

Selye H. (1979). Stress bez distressa. - Moskva: Progress, p. 123

Selye H. (1956). The Stress of Life. New York: McGraw-Hill

Tashheva A.I. (2000). Enciklopedija psihologicheskoj pomoshchi. Rostov n/D., p. 20.

Taylor, Shelley, and Sirois, Fuschia. (2012). Health Psychology 2nd Canadian Edition

Wrzus C, Müller V, Wagner GG, Lindenberger U, Riediger M. (2013). Affective and cardiovascular responding to unpleasant events from adolescence to old age: complexity of events matters. Dev Psychol. Feb; 49(2):384-97.

Yamada C, Sadakane C, Nahata M, Saegusa Y, Nakagawa K, Okubo N, et al. (2015). Serotonin 2C receptor contributes to gender differences in stress-induced hypophagia in aged mice. Psychoneuroendocrinology. 55:81-93. Epub: 2015/03/04. pmid: 25732068.).

How to cite this article: Bogdan T (2017). Estimation of the Stress Index in Patients of Different Age Categories. International Journal of Indian Psychology, Vol. 5, (1), DIP: 18.01.102/20170501, DOI: 10.25215/0501.102 